\title{
Comparison of Conductivity Performance of Dragon Fruit Dye Extracted Using Water and Ethanol for Dye Sensitized Solar Cells
}

\author{
Rosnah Zakaria ${ }^{1,2, *}$, Oskar Hasdinor Hassan ${ }^{3}$, Muhd Zu Azhan Yahya ${ }^{2,4}$, Mohamad Fariz Mohamad Taib ${ }^{1,2}$ and Ab \\ Malik Marwan Ali ${ }^{1}$
}

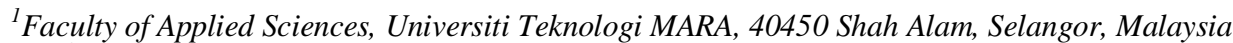

${ }^{2}$ Institute of Science, Universiti Teknologi MARA, 40450 Shah Alam, Selangor, Malaysia

${ }^{3}$ Faculty of Art and Design, Universiti Teknologi MARA, 40450 Shah Alam, Selangor, Malaysia

${ }^{4}$ Faculty of Defence Science \& Technology, Universiti Pertahanan Nasional Malaysia, 57000

*Corresponding author E-mail: rosna593@salam.uitm.edu.my

\begin{abstract}
Natural pigments such as anthocyanin, carotenoid, flavonoids, and chlorophyll can be considered as promising alternative sensitizer dyes for DSSC to replace synthetic dye such as N719 because of their simple preparation technique, low cost, complete biodegradation, availability, purity grade, environmental friendliness and most importantly ability to reduce noble metal. In this work, UV-Vis spectra is used to observe the absorption spectra of different extracting solvent of dragon fruit dye. Fourier Transform Infrared Spectroscopy (FTIR) identifies the functional components of the dye while impedance spectroscopy gives the conductivity data. Dragon fruit dye extracted with ethanol had a lower absorbance at $518 \mathrm{~nm}$ compared to dragon fruit dye extracted with distilled water at $521 \mathrm{~nm}$. The presence of carboxyl group in Betalains pigment within the range of $400-700 \mathrm{~nm}$ wavenumber promotes strong hydrogen bonding while the presence of $\mathrm{COOH}$ stretching vibration further confirms the carboxyl group of Betalains derivatives in dragon fruit dye. The electrical conductivity measured at room temperature $\left(27^{\circ} \mathrm{C}\right)$, boiling point $\left(100^{\circ} \mathrm{C}\right)$ and $130^{\circ} \mathrm{C}$ recorded highest value of $183 \mathrm{Scm}^{-1}$ at $100{ }^{\circ} \mathrm{C}$ for dragon fruit dye diluted with distilled water (D-DI) while for dragon fruit dye diluted with ethanol (D-Etha) the value is $9.56 \times 10^{-1} \mathrm{Scm}^{-1}$ at $130^{\circ} \mathrm{C}$ hence showing that distilled water is the best solvent for natural dye from dragon fruit.
\end{abstract}

Keywords: absorption spectra, conductivity, carboxyl group, dragon fruit dye, solvent.

\section{Introduction}

Natural pigments have been considered as promising alternative sensitizer dyes for DSSC because of their simple preparation technique, low cost, complete biodegradation, availability, purity grade, environmental friendliness, and most importantly, high reduction of noble metal and chemical synthesis cost. Natural colorants are pigmentary molecules and dyes obtained mainly from plants such as chlorophyll, carotenoid, anthocyanin, flavonoid, cyanine, and tannin (Ludin et al., 2014).

Dragon fruit known as Hylocereus undatus is a tropical fruit popular in Southeast Asia, belonging to the climbing cacti (Cactaceae) family (Castro et al., 2017). Dragon fruit contains a lot of vitamin $\mathrm{C}$ and is said to aid in digestion. Dragon fruit, also known as pitaya or pitahaya grows on a veining epiphytic cactus (Hylocereus sp.) native to the tropical forest regions of Mexico and Central and South America (Syafinar R et al 2015). The flesh of the fruit is red-purple in color when ripened with minute black seeds interspersed and has gained a growing interest for cultivation in Malaysia (Hoa et al., 2006). This fruit has gained much interest in the society because of its exotic features, attractive colors, nutritional value and pleasant taste (Bellec et al., 2006).
Ultraviolet and visible spectrometers have been in general use for the last 35 years and over this period have become the most important analytical instrument nowadays which can indicate the presence of anthocyanins in the fruit (Mozaffari, Saeidi, \& Rahmanian, 2015). However, the molecular fingerprint can be determined through Fourier Transform Infrared Spectroscopy (FTIR) characterization (Syafinar R et al, 2015). In the infrared spectroscopy technique, infrared radiation will pass through the sample where some of the infrared radiations were absorbed and some were transmitted. The absorption and transmission of the infrared radiation by the sample will create a molecular fingerprint EIS is a promising technique to measure the electrical impedance of a substance as a function of the frequency of an applied electrical current by using alternating current. It is also used to study the effects of interface modification on the electron transport and recombination kinetics of the dye-sensitized solar cell including chemical capacitance $\left(\mathrm{C}_{\mu}\right)$ at the $\mathrm{TiO}_{2} /$ dye/electrolyte interface, recombination resistance $\left(\mathrm{R}_{\text {rec }}\right)$ and electron transport resistance $\left(\mathrm{R}_{\mathrm{t}}\right)$ (Luo et al., 2016)

\section{Methodology}

Two samples were prepared. The first sample, D-DI is a mixture of $10 \mathrm{~g}$ of dragon fruit with $15 \mathrm{ml}$ of distilled water as the solvent. 
The second sample, D-Etha is a mixture of $10 \mathrm{ml}$ ethanol and $10 \mathrm{~g}$ of the dragon fruit. Both samples were centrifuged at $10000 \mathrm{rpm}$ for 10 minutes. A dropper was used to collect dragon fruit dye pigment at the center of the test tube before undergoing Ultraviolet-visible Spectroscopy (UV-Vis) and Fourier Transform Infrared Spectroscopy (FTIR) analysis.

Meanwhile, ITO glass was sequentially cleaned in distilled water, acetone and ethanol using an ultrasonic bath. The ITO-coated glass was first dried in an oven at $44^{\circ} \mathrm{C}$ for 24 hours. It was covered with two parallel adhesive tapes $1 \mathrm{~cm}$ apart to control the thickness and the area of the $\mathrm{TiO}_{2}$ film $(1.8 \mathrm{~cm} \mathrm{X} 1.0 \mathrm{~cm})$. Before coating with $\mathrm{TiO}_{2}$ paste, the ITO glass was tested with a multimeter to check the conductive side. Then, the $\mathrm{TiO}_{2}$ paste was coated onto the ITO glass substrate using Doctor Blade technique. The $\mathrm{TiO}_{2}$ coated films were heated at $450^{\circ} \mathrm{C}$ for $30 \mathrm{~min}$ and left to dry for 2 days at room temperature. Then, two ITO coated glasses were soaked for 24 hours in a dark environment in dragon fruit mixture, D-DI, and D-Etha separately. Lastly, the samples were washed away of any residue using ethanol and further dried at $60^{\circ} \mathrm{C}$ before undergoing characterization by EIS.

\section{Results and Discussion}

\subsection{Uv-Vis Absorption Spectra}

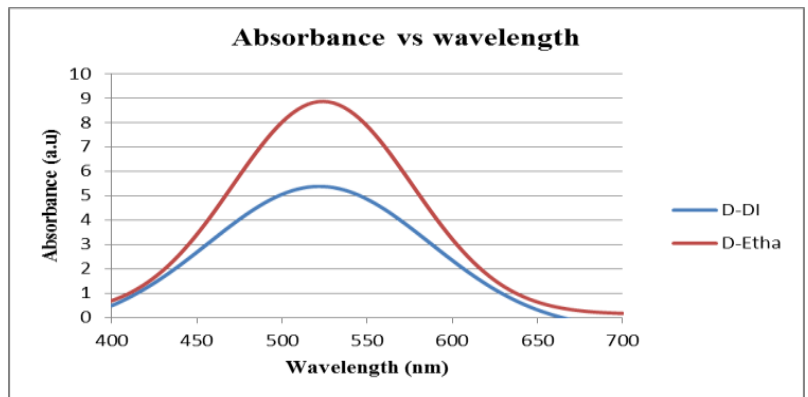

Fig 1:Absorbance spectra of dragon fruit dye diluted with distilled water (D-DI) and ethanol (D-Etha)

Fig. 1 shows the absorption spectra of D-DI and D-Etha which shows the ability of the dye solutions to absorb photon from visible light. The absorption range of $470 \mathrm{~nm}$ to $600 \mathrm{~nm}$ is attributed to the existence of betalains pigments in dragon fruit's dye. Betalains have antioxidant properties which favors to absorb light and capable of complexing with metal ions which can modify their light absorbing properties because that pigment exists in nature in association with various copigments (Zhang et al. 2014). Dragon fruit's dye extracted using ethanol have lower absorbance compared to dragon fruit that has been diluted with distilled water. Maximum absorption wavelength obtained by DDI is $521 \mathrm{~nm}$, which is slightly higher than that of D-Etha which has a peak wavelength at $518 \mathrm{~nm}$.

\subsection{Fourier Transform Infrared Spectroscopy (FTIR)}

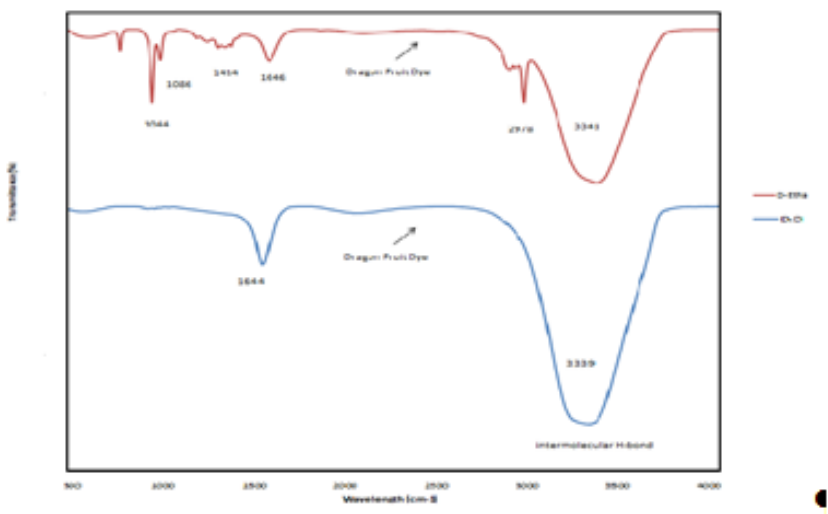

Fig 2: FTIR spectrum of D-DI and D-Etha
The dye solution for dragon fruit diluted with ethanol (D-Etha) showed a peak at $1044 \mathrm{~cm}^{-1}$ due to C-O stretching vibration. The peak at $1454 \mathrm{~cm}^{-1}$ corresponds to the aromatic group contained in $\mathrm{C}-\mathrm{C}$ stretching. Besides that, the peak at $1646 \mathrm{~cm}^{-1}$ corresponds to $\mathrm{C}=\mathrm{O}$ stretching vibration which represents the carbonyl group of ketone structure. The peak at $3341 \mathrm{~cm}^{-1}$ is due to hydroxyl O-H group in the dragon fruit dye. In the case of dragon fruit diluted with distilled water (D-DI), the peak at $1644 \mathrm{~cm}^{-1}$ represents $\mathrm{C}=\mathrm{O}$ vibration and the peak of $3339 \mathrm{~cm}^{-1}$, corresponds to $\mathrm{O}-\mathrm{H}$ stretching vibrations.

These results are in agreement with the results presented by Ahmad et al., (2010) who obtained a broad absorption range between 3200 3400 $\mathrm{cm}^{-1}$, sharp adsorption between 1600 1700 $\mathrm{cm}^{-1}$ and a sharp peak between $1030 \sim 1060 \mathrm{~cm}^{-1}$ as observed in DDI sample. Other than that ,D-Etha showed a peak at $3031 \mathrm{~cm}^{-1}$ attributed to $\mathrm{O}-\mathrm{H}$ group which is the hydroxyl group in dragon fruit dye and a broad peak at $3400 \mathrm{~cm}^{-1}$ which corresponds to OH stretching (Syafinar R et al., 2015).

Hence, active components are present in the dragon fruit dye investigated in this work and these are $\mathrm{C}=\mathrm{O}$ (attributed to carbonyl) and $\mathrm{O}-\mathrm{H}$ (corresponds to the hydroxyl group) usually in a carboxylic acid form. The presence of Carboxyl group contained in betalains pigment promotes strong hydrogen bonding. The presence of $\mathrm{COOH}$ stretching vibration confirms the carboxyl group in Betalains derivatives and is well matched with the UVVis absorption spectra. The range of absorption in the visible light spectrum of betalains pigment is in the range between $400 \mathrm{~nm}$ and $700 \mathrm{~nm}$ which corresponds to the betacyanins and betaxanthins in betalains pigment which promotes a stronger electron coupling bond (Ahmad et al. 2010).

\subsection{Electrochemical Impedance Spectroscopy (Eis)}

Table 1: Conductivity measurement of dragon fruit dye with distilled water-D-DI

\begin{tabular}{|c|c|c|}
\hline $\begin{array}{c}\text { Temperature } \\
\left({ }^{\circ} \mathbf{C}\right)\end{array}$ & $\begin{array}{c}\text { Bulk resistance, } \mathbf{R}_{\mathbf{b}} \\
(\mathbf{\Omega})\end{array}$ & $\begin{array}{c}\text { Conductivity, } \boldsymbol{\sigma} \\
\left.\mathbf{( S c m}^{-1}\right)\end{array}$ \\
\hline $\mathbf{2 7}$ & $1.057 \times 10^{3}$ & $7.41 \times 10^{-1}$ \\
\hline $\mathbf{1 0 0}$ & $0.416 \times 10^{3}$ & $1.83 \times 10^{0}$ \\
\hline $\mathbf{1 3 0}$ & $0.423 \times 10^{3}$ & $1.80 \times 10^{0}$ \\
\hline
\end{tabular}

Table 2: Conductivity measurement of dragon fruit dye with ethanol- DEtha

\begin{tabular}{|c|c|c|}
\hline Temperature $\left({ }^{\circ} \mathbf{C}\right)$ & Bulk resistance, $\mathbf{R}_{\mathbf{b}}(\mathbf{\Omega})$ & $\begin{array}{c}\text { Conductivity, } \\
\boldsymbol{\sigma}\left(\mathbf{S c m}^{-1}\right)\end{array}$ \\
\hline $\mathbf{2 7}$ & $4.384 \times 10^{3}$ & $1.724 \times 10^{-1}$ \\
\hline $\mathbf{1 0 0}$ & $1.163 \times 10^{3}$ & $6.563 \times 10^{-1}$ \\
\hline $\mathbf{1 3 0}$ & $0.834 \times 10^{3}$ & $9.556 \times 10^{-1}$ \\
\hline
\end{tabular}

The conductivity was measured at room temperature, $27^{\circ} \mathrm{C}$, boiling point, $100^{\circ} \mathrm{C}$ and $130^{\circ} \mathrm{C}$. The conductivity for both sampleswas found to increase with increase in temperature. This happened because the samples absorbed heat which is converted to electrical energy (Laily et al., 2016).

The highest conductivity is $183 \mathrm{Scm}^{-1}$ at $100^{\circ} \mathrm{C}$ obtained from the sample of dragon fruit dye extracted with distilled water. Overall, the conductivity of dragon fruit dye with distilled water, slightly decreased as the temperature increased to $130^{\circ} \mathrm{C}$. The lowest conductivity obtained is $1.724 \times 10^{-1} \mathrm{Scm}^{-1}$ from the sample of dragon fruit dye extracted with ethanol at room temperature. Hence, the dragon fruit dye with distilled water shows higher conductivity compared to the dragon fruit dye with ethanol.

\section{Conclusion}

UV-Vis analysis showed that the dragon fruit dye with ethanol obtained lower absorbance at $518 \mathrm{~nm}$ compared to dragon fruit diluted with distilled water at $521 \mathrm{~nm}$. The UV-Vis absorption spectra have measured the ability of the dye to absorb a photon in visible light spectrum.

- Based on the results of FTIR spectra, the samples showed the presence of functional group of active components in extracting 
dye. Besides that, a dye extracted from dragon fruit contained $\mathrm{C}=\mathrm{O}$ stretching vibration peak at $1646 \mathrm{~cm}^{-1}$ and a peak at $3341 \mathrm{~cm}^{-}$

${ }^{1}$ due to $\mathrm{O}-\mathrm{H}$ stretching vibration. From the FT-IR results, the existence of $\mathrm{CO}=\mathrm{OH}$ corresponding to carboxylic group in Betalain's pigment of Dragon fruit's dye is substantiated.

The conductivity of extracted dye was measured using impedance spectroscopy. The highest electrical conductivity belong to dragon fruit dye diluted with distilled water (D-DI), which is $183 \mathrm{Scm}^{-1}$ at $100{ }^{\circ} \mathrm{C}$ and for dragon fruit dye diluted with ethanol (D-Etha) the value is $9.56 \times 10^{-1} \mathrm{Scm}^{-1}$ at $130^{\circ} \mathrm{C}$. It showed that distilled water is the best solvent for the natural dye from dragon fruit.

However, natural dye can be easily degraded but could probably be improved by adding stabilizers like antioxidants, such as vitamin C or E (Hoa et al., 2006). Besides that, natural dye can be extracted from various parts of a plant such as the flower, fruit, leaf and root that contains strong color. Various types of extraction solvent can be used in dye extraction to maintain the color of natural dye.

\section{Acknowledgement}

The authors gratefully acknowledge the help of the Ministry of Higher Education (MOHE) of Malaysia in providing financial support under the project FRGS/1/2015/SG06/UITM/02/5 grant and Universiti Teknologi MARA (UiTM) for the facilities provided

\section{Reference}

[1] Ahmad, R., Ali, M., \& Nayan, N. (2010). Fabrication and analysis of dye-sensitized solar cell using natural dye extracted from dragon fruit. International Journal of Integrated Engineering, 3(3),1-8.

[2] Bellec, F.L.; Vaillant, F.; Imbert, E. (2006). Pitahaya (Hylocereus spp.): a new fruit crop, a market with a future. Fruits 61: 237- 250.

[3] Castro, J. C., Endo, E. H., de Souza, M. R., Zanqueta, E. B., Polonio, J. C., Pamphile, J. A., Abreu Filho, B. A. d. (2017). Bioactivity of essential oils in the control of Alternaria alternata in dragon fruit (Hylocereus undatus Haw.). Industrial Crops and Products, 97, 101-109. doi: http://dx.doi.org/10.1016/j.indcrop.2016.12.007

[4] Hoa, T.T.; Clark, C.J.; Waddell, B.C.; Woolf, A.B. (2006). Postharvest quality of dragon fruit (Hylocereus undatus) following disinfesting hot air treatments. Postharvest Biology and Technology 41: 62- 69 .

[5] Laily, A. R. N., Hasiah, S., Aziz, N. A. N., \& Dagang, A. N. (2016) Poly (3-Dodecylthiophene)/Natural Dye Bulk Heterojunction Organic Solar Cell: An Electrical Conductivity, and Hall Effect Study. Procedia Chemistry, 19, 2-9. doi: http://dx.doi.org/10.1016/j.proche.2016.03.003

[6] Ludin, N. A., Al-Alwani Mahmoud, A. M., Bakar Mohamad, A. Kadhum, A. A. H., Sopian, K., \& Abdul Karim, N. S. (2014). Review on the development of natural dye photosensitizer for dyesensitized solar cells. Renewable and Sustainable Energy Reviews, 31, 386-396. doi: 10.1016/j.rser.2013.12.001

[7] Luo, J., Wan, Z., Jia, C., Wang, Y., Wu, X., \& Yao, X. (2016). Cosensitization of Dithiafulvenyl-Phenothiazine Based Organic Dyes with N719 for Efficient Dye-Sensitized Solar Cells. Electrochimica Acta, 211, 364-374. doi: http://dx.doi.org/10.1016/j.electacta.2016.05.175

[8] Syafinar, R., Gomesh, N., Irwanto, M., Fareq, M., \& Irwan, Y. (2015). Cocktail Dyes From Blueberry And Dragon Fruit In The Application For Dssc. ARPN Journal of Engineering And Applied Sciences, Vol.10, No15, ISBN 1819-6608

[9] Syafinar, R., Gomesh, N., Irwanto, M., Fareq, M., \& Irwan, Y. (2015). FT-IR AND UV-VIS Spectroscopy Photochemical Analysis Of Dragon Fruit. ARPN Journal of Engineering And Applied Sciences, Vol.10, No15, ISBN 1819-6608

[10] Mozaffari, S. A., Saeidi, M., \& Rahmanian, R. (2015) Photoelectric characterization of fabricated dye-sensitized solar cell using dye extracted from red Siahkooti fruit as natural sensitizer. Spectrochim Acta A Mol Biomol Spectrosc, 142, 226-231. doi: 10.1016/j.saa.2015.02.003

[11] Zhang, L., Liu, F., Brinkman, K., Reifsnider, K. L., \& Virkar, A. V. (2014). A study of gadolinia-doped ceria electrolyte by electrochemical impedance spectroscopy. Journal of Power Sources, 247, 947-960 